\title{
Study on Recycling Garments Wastage as an Alternative Sizing Material
}

\author{
Moin Uddin', Jabed Hossen Emon ${ }^{2 *}$, Jonaetul Kibria Niloy ${ }^{3}$ \\ ${ }^{1}$ Directorate of Technical Education, Dhaka, Bangladesh \\ ${ }^{2}$ Department of Textile Engineering, Uttara University, Dhaka, Bangladesh \\ ${ }^{3}$ Department of Wet Processing Engineering, Textile Engineering College, Zorargonj, Chattogram, Bangladesh \\ Email: *jabedhossenemon@gmail.com
}

How to cite this paper: Uddin, M., Emon, J.H. and Niloy, J.K. (2022) Study on Recycling Garments Wastage as an Alternative Sizing Material. Journal of Textile Science and Technology, 8, 15-24. https://doi.org/10.4236/jtst.2022.81002

Received: December 12, 2021

Accepted: February 5, 2022

Published: February 8, 2022

Copyright (c) 2022 by author(s) and Scientific Research Publishing Inc. This work is licensed under the Creative Commons Attribution-NonCommercial International License (CC BY-NC 4.0). http://creativecommons.org/licenses/by-nc/4.0/ (c) (i) \$) Open Access

\begin{abstract}
This paper deals with garments wastage, which could proficiently assess alternative sizing materials than conventional sizing materials. In this research, the synthesized Carboxymethyl Cellulose (CMC) was originated from garments wastages and after that, synthesized CMC and exported CMC were added in sizing recipe for newly sized yarn and conventionally sized yarn respectively. Yarn count, strength, CSP, desizing efficiency and dye absorbency have been evaluated and a comparison has been made among the samples. Less count variation was found in newly sized yarn and a desirable amount of strength \& CSP were also acquired in newly sized yarn but it was slightly less than the conventional one. After desizing and dye absorbency test, it has shown a favorable character for further steps like dyeing, printing, etc. These findings convey that synthesized CMC prepared from garments wastage in this study are good candidates for alternative sizing agents.
\end{abstract}

\section{Keywords}

Garment Wastages, Carboxymethyl Cellulose (CMC), Sizing, Strength, CSP

\section{Introduction}

Sizing, heart of weaving, is one of the crucial processes in textile industry. It is an essential process for warp yarn before weaving in order to enhance the strength of the yarn [1]. The warp yarn needs to be sized as this yarn undergo various force during weaving which can enhance breakage rate [2]. If there is a defect in the sizing, the quality of the warp yarn will be worse which may enormously affect the quality of the fabric and the weaving operation. The performance of warp yarn largely depends on the nature of the protective coating [3]. Modern 
sizing technology helps to the reduction of using energy and sizing agents, the increasing of loom productivity and the enhancement of the sized yarn properties [4]. Starch, PVA, CMC are the main sizing ingredients. CMC is used extensively in textile sector and other industrial fields including cosmetics, paper, pharmaceuticals, food products and adhesives [5]. In Bangladesh, a large amount of CMC is imported every year to meet its demand for textile sector as it is a textile industry-based country and the importance of CMC is increasing day by day [6].

Previously research works were done showing the process of synthesis and grafting of Carboxymethyl Cellulose from environmental pollutant cellulosic wastes of textile industry [7], indigenous cotton linters [8], sago waste [9] and water hyacinth using isobutyl-ethanol mixture [10]. Some authors have studied that animal fats mixing with different concentrations of acids could effectively assess alternative sizing agents instead of conventional sizing materials [11]. In a study, plant proteins and chicken feathers are offered an economical alternative to replace starches, CMC, PVA and other substances for sizing cotton yarn [12]. In another study, a comparative study was established based on the properties of sized yarn and fabric using PVA and maize starch as sizing agents [13]. The improvement of strength and interface properties of CFs/EP composites were analysed by the modification of CFs surface with CMC [14]. Several authors have also examined that the physio-mechanical, chemical and dyeing properties can be increased remarkably by applying $\mathrm{CMC}, \mathrm{CMC}-\mathrm{g}$-PVA or CMC/PVA as sizing and finishing additives [15].

The aim of this study was to recycle those fabric wastages in sizing process by preparing Carboxymethyl Cellulose (CMC). Every year textile fabric producing county of the world import sizing materials from outside and spend a massive amount of money. This fabric wastage also comes up with an alarming rate of pollution causing in landfills and creating smoke when people burn it for various purposes. If synthesized CMC can be produced through the process that we utilized and it can be applied to the sizing process, then a massive amount of money can be saved as well as environmental pollution can also be mitigated.

\section{Materials and Methods}

\subsection{Materials}

In this experiment, unsized yarn and conventionally sized yarn of $100 \%$ cotton were collected from Regent Textile Mill, Kalurghat, Chattogram whose count was $30 \mathrm{Ne}$ and produced from $28.5 \mathrm{~mm}$ length and $4.2 \mathrm{mic}$ fibre. Specification of

Table 1. Specification of $100 \%$ cotton yarn.

\begin{tabular}{cccccccc}
$\begin{array}{c}\text { Yarn } \\
\text { Properties }\end{array}$ & $\mathrm{U} \%$ & $\mathrm{CV}_{\mathrm{m}}$ & $\begin{array}{c}\text { Thin } \\
(-50 \%) / \mathrm{km}\end{array}$ & $\begin{array}{c}\text { Thick } \\
(+50 \%) / \mathrm{km}\end{array}$ & $\begin{array}{c}\text { Neps } \\
(+200 \%) / \mathrm{km}\end{array}$ & IPI Hairiness \\
\hline Value & 12.83 & 16.32 & 17 & 259.5 & 453.5 & 730 & 7.17 \\
\hline
\end{tabular}


$100 \%$ cotton yarn is given below in Table 1. Garments wastes (Fabric), Ethanol, Sodium Hydroxide, Monochloroacetic Acid, Wetting Agent, Anti creasing Agent, Distilled water, wax, Glycerin, etc. also collected from the same factory.

\subsection{Methodology}

\subsubsection{Preparation of CMC from Garments Wastages}

\section{In First Step,}

Fabric wastes received from garments

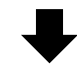

Fabric wastes were loaded and run for 5 - 10 minutes at normal temperature

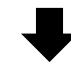

Wetting agent, anti-creasing agent were added at a time for 5 minutes

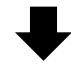

Caustic was dosing at normal temperature for 5 minutes

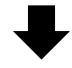

Run for 10 minutes

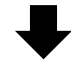

Temperature was increased at $110^{\circ} \mathrm{C}$ and continued for 40 minutes

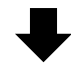

Cooling at $80^{\circ} \mathrm{C}$

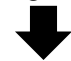

Hydrose inject for 5 minutes

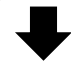

Temperature was also increased at $110^{\circ} \mathrm{C}$ for 10 minutes

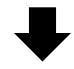

30 minutes cooling was done at $80^{\circ} \mathrm{C}$

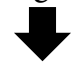

Sample check

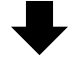

Rinsing for 15 minutes

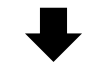

Hot wash

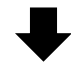

Cold wash

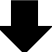

Unload the fabric wastes

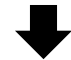

Sliced the fabric wastages

After completing $1^{\text {st }}$ step, colored garments wastages are turned into white sliced fabric wastages which are given below in Figure 1.

In Final Step, 
$5 \mathrm{ml}$ of Monochloroacetic Acid was added drop by drop in the mixture at $60^{\circ} \mathrm{C}$

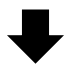

Run for 6 hours

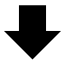

the samples were collected by filtration and washed with $80 \%$ ethanol solution

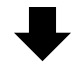

These two steps were repeated for four times as the single step gave low DS (Degree of substitution) CMC

After completion of these four steps, garments waste turned into powder form and engendered Carboxymethyl Cellulose (CMC) which is given below in Figure 2.

\subsubsection{Sizing of Cotton Yarn}

Sizing of cotton yarn was done with CMC following the recipe shown in Table 2. At first, water was added to the mixing tank before the recipe was added. The temperature was raised with steam to $90^{\circ} \mathrm{C}$ and stirred for $20 \mathrm{~min}$ before it was released into the size box. Unsized yarn \& conventionally sized yarn is also shown in Figure 3 \& Figure 4 respectively and newly sized yarn is shown in Figure 5.

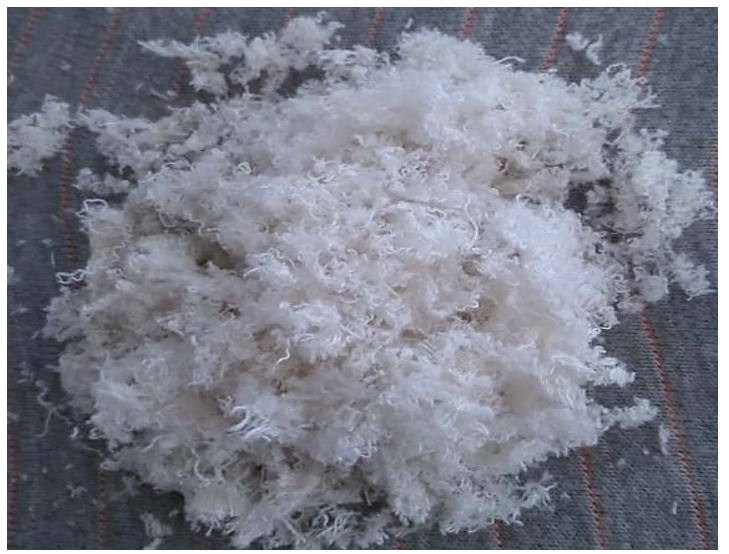

Figure 1. Sliced fabric wastages (after first step).

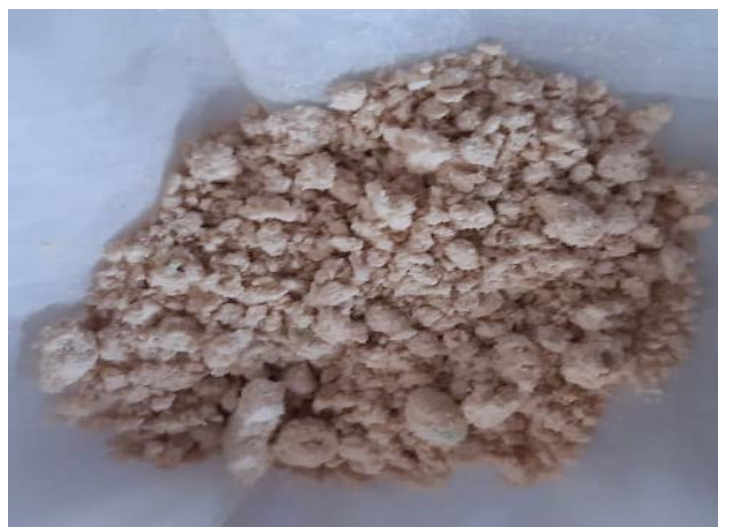

Figure 2. CMC from garments wastes (after final step). 
Table 2. Sizing recipe for factory sized yarn \& newly sized yarn.

\begin{tabular}{cc}
\hline Components & Value \\
\hline Starch & $25 \mathrm{~g}$ \\
Exported CMC for factory sized yarn/Synthesized CMC for newly sized yarn & $4 \mathrm{~g}$ \\
Binder & $2 \mathrm{~g}$ \\
Wax & $2 \mathrm{~g}$ \\
Water & $250 \mathrm{ml}$ \\
Steam & $30 \mathrm{ml}$ \\
\hline
\end{tabular}

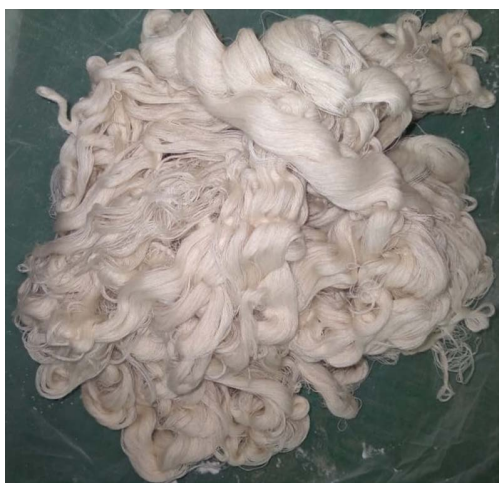

Figure 3. Unsized yarn.

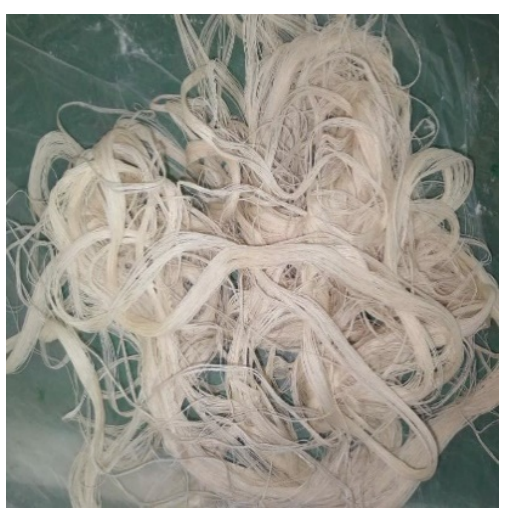

Figure 4. Conventionally sized yarn.

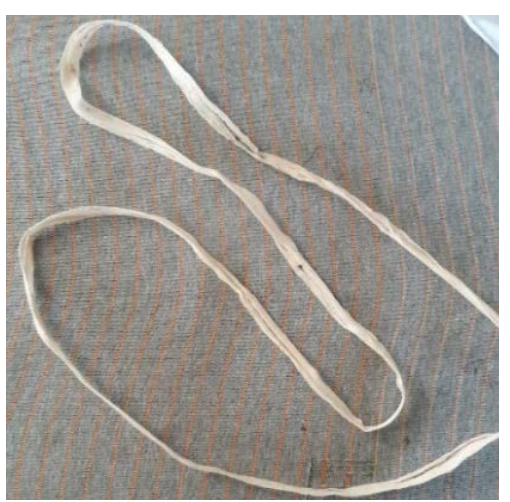

Figure 5. Newly sized yarn. 


\subsubsection{Measurement of Sized Yarn Count}

Beesley balance was used to determine sized yarn count.

Firstly, the yarn sample was cut by knife's according to the template size. A standard weight is hung in a notch on the beam arm on the pointer side of the pivot. A template is used to cut short lengths of yarn, the length depending upon the count system required. These short lengths are placed sample hook until the pointer comes in level with the balanced line. The number of short length yarn required to balance both sides is the count of the yarn.

\subsubsection{Measurement of Sized Yarn Strength and Count Strength Product (CSP)}

For strength calculation, Lea Strength Tester machine was used.

At first, 1 lea (120 yards) yarn was measured by using Auto Wrap Reel. The machine was fixed to 80 revolutions to make 120 yards, a lea is formed when it completes 80 turns. Then set the yarn in Lea Strength Machine and get the reading at that breaking point giving the reading of yarn strength in pounds. By multiplying this value with yarn count, CSP (Count Strength Product) was determined.

\subsubsection{Preparation of Desizing Recipe}

Desizing was done enzymatically with the recipe prepared as shown in Table 3 and pumped into the desizing machine. A conventional method was applied for desizing.

\subsubsection{Measurement of Dye Absorbency Test}

For dye absorbency test, at first, $1000 \mathrm{ml}$ water along with $1 \mathrm{~g}$ reactive dyes was added in conical flax and stir them properly to make a solution. At the same time, some slightly twisted desized yarn was taken and put 5 marks on the yarn surface (each mark $1 \mathrm{~cm}$ ). Then submerge the yarn into the solution up to $1 \mathrm{~cm}$ for 1 minute and saw how much the colorant water claims up through the yarn. A rating was made depending on how much the colorant water claims up through the yarn such as if the colorant water takes up more than 3 times of its submerge length, it was rated 4 out of 5 .

Table 3. Desizing recipe.

\begin{tabular}{cc}
\hline Components & Value \\
\hline Invazyme ADC (Enzyme) & $3 \mathrm{~g} / \mathrm{l}$ \\
DLC (Wetting \& Detergent) & $3 \mathrm{~g} / \mathrm{l}$ \\
NEO (Sequestering Agent) & $0.5 \mathrm{~g} / \mathrm{l}$ \\
$\mathrm{P}^{\mathrm{H}}$ & $5.5-6.5$ \\
Temperature & $80^{\circ} \mathrm{C}$ \\
Dwelling Time & $8-12 \mathrm{hours}$ \\
Speed & $50-60 \mathrm{~m} / \mathrm{min}$ \\
\hline
\end{tabular}




\section{Results and Discussions}

\subsection{Effect of Sizing Material on Warp Yarn Count}

Figure 6 clearly represents the count variation among unsized yarn, conventionally sized yarn and newly sized yarn. It is found that variation of newly sized yarn count is less than the conventionally sized yarn count compared to unsized yarn count. Basic advantage here is, no longer have to rely on exported CMC and the garments wastages can be assessed as raw materials which have a clear environmental lead.

\subsection{Effect of Sizing Material on Warp Yarn Strength \& CSP}

CSP is another parameter to calculate and compare strength. After testing strength and multiplying with count we got following CSP:

Unsized yarn strength $=78.5 \quad$ Unsized yarn CSP $=78.5 \times 30=2355$

Conventional sized yarn $=89 \quad$ Conventional sized yarn CSP $=89 \times 27=$ 2403

Newly sized yarn strength $=85.5 \quad$ Newly sized yarn CSP $=85.5 \times 28=2394$

Figure 7 clearly represents the changes in strength and CSP among sample yarn, conventionally sized yarn and newly sized yarn. Certainly, it is observed that strength of conventionally sized yarn sample is slightly greater than newly sized yarn sample. That's why newly sized yarn has shown slightly less CSP value. This difference will not create any effect during the weaving process. Environmental gain and less dependence on exported CMC would mitigate the difference in output between the newly sized and factory sized yarn.

\subsection{Effect of Sizing Material on Warp Yarn Dye Absorbency}

After absorbing both warp yarn to the reactive dye solution, the colorant water takes up more than 3 times of its submerge length. Newly sized yarn after

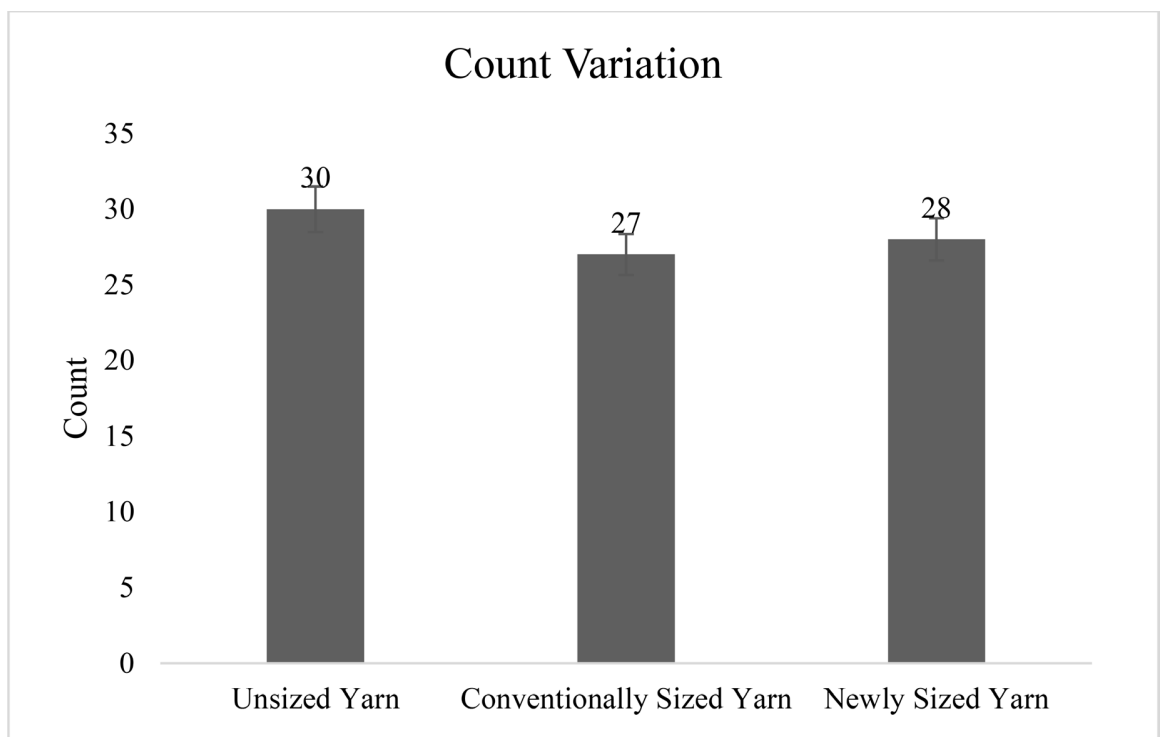

Figure 6. Effect of sizing material on warp yarn count. 


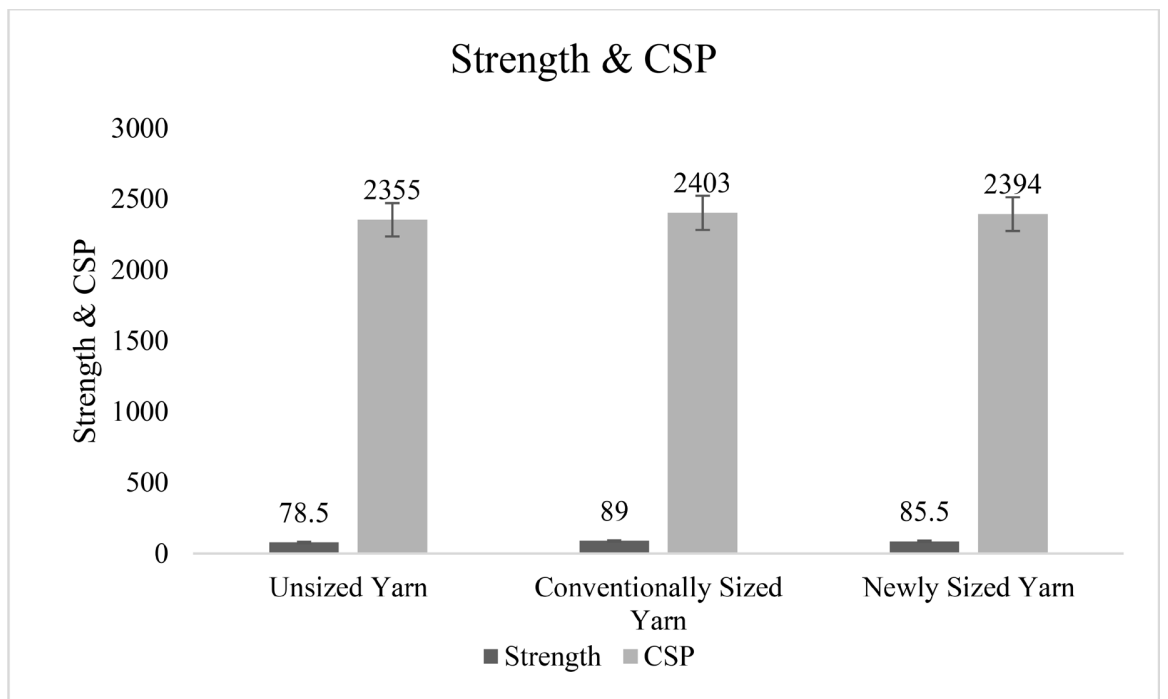

Figure 7. Effect of sizing material on warp yarn strength \& CSP.

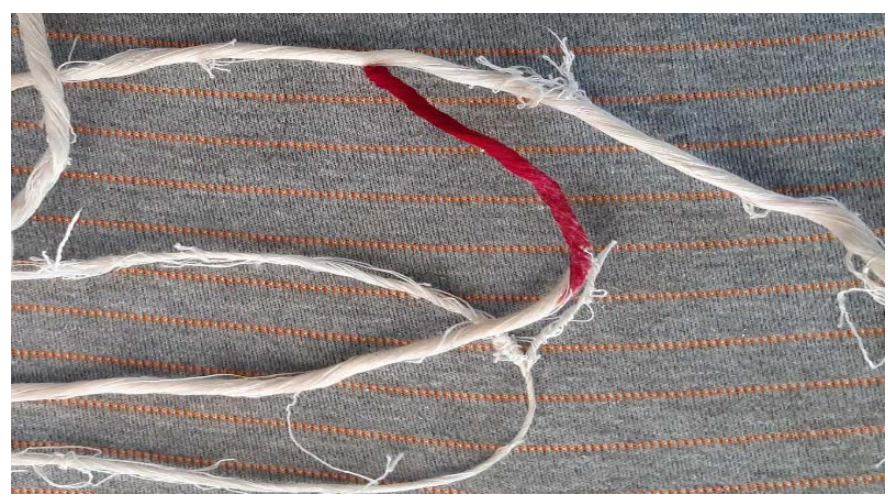

Figure 8. Newly sized yarn after absorbency test.

dye absorbency is shown in Figure 8. So,

Dye absorbency rating of newly sized yarn $=4$ out of 5 ;

Dye absorbency rating of conventionally sized yarn $=4$ out of 5 .

The rate for dye absorbency was same for every aspect and no significant changes were made to the both sized yarns. So, exported CMC can be replaced easily by synthesized CMC produced from garment wastages.

\subsection{Effect of Sizing Material on Warp Yarn Desizing Efficiency}

After desizing following test is conducted to ensure desizing.

In treatment of cotton yarn with Potassium Iodide (KI) - presence of starch in yarn is indicated by the presence of blue color.

Rating of conventionally sized yarn for desizing efficiency test $=4$ out of 5 ;

Rating of newly sized yarn for desizing efficiency test $=4$ out of 5 .

After desizing, both of the sized yarns were shown same rating.

\section{Conclusion}

Carboxymethyl Cellulose which is an integral material for textile industries can 
be produced from garments wastes and can be used for sizing. So, the expenditure for importing CMC can be reduced significantly. Local industries can go for industrial production of CMC by using this method. This process is environmentally friendly too cause the pollutants are used for production. Sized yarn by newly produced CMC gives a favourable amount of strength, count, CSP, absorbency test and desizing identification test in comparison with conventionally sized yarn. So, this synthesized CMC can be used for sizing process. After desizing, it also shows an optimal result. A desirable amount of sizing material was reduced after soaking the yarn into solution. In absorbency test, it shows a satisfying result. So, this whole process can be used for the industrial production of CMC from garments wastes. Synthesized CMC can be used in sizing process of textile industries and a desirable amount of strength, count, CSP, absorbency and efficiency after desizing can be found from it.

\section{Acknowledgements}

The authors would like to thank all technical staff and top management of Regent Textile Mills industry for their support and guidance for this research.

\section{Conflicts of Interest}

The authors declare no conflicts of interest regarding the publication of this paper.

\section{References}

[1] Takebira, U.M., Mohibullah, A.T.M., Hossain, M.Z., Tanim, S.I., Redoy, M.S.A., Rahman, M.L. and Rejwan, M.S. (2020) A Regular Study on Yarn Count, Size Box Temperature and Machine Speed to Increase Weaving Efficiency of Cotton Fabric. Journal of Textile Science and Technology, 6, 168-176. https://doi.org/10.4236/jtst.2020.64014

[2] Maatoug, S., Ladhari, N. and Sakli, F. (2007) Evaluation of the Weavability of Sized Cotton Warps. Autex Research Journal, 8, 239-244.

[3] Goswami, B.C., Rajesh, D.A. and Hall, D. (2004) Textile Sizing. CRC Press, New York. https://doi.org/10.1201/9780203913543

[4] Kovačević, S. and Penava, Ž. (2004) Impact of Sizing on Physico-Mechanical Properties of Yarn. Fibres \& Textiles in Eastern Europe, 48, 32-36.

[5] Bokias, G., Mylonas, Y., Staikos, G., Bumbu, G.G. and Vasile, C. (2000) Synthesis and Aqueous Solution Properties of Novel Thermoresponsive Graft Copolymers Based on a Carboxymethylcellulose Backbone. Macromolecules, 34, 4958-4964. https://doi.org/10.1021/ma010154e

[6] Parikh, D.V., Sachinvala, N.D., Calamari, T.A. and Negulescu, I. (2003) Carboxymethylated Cotton for Moist Wound Healing. AATCC Review, 3, 15-19.

[7] Mondal, M.I.H. and Ahmed, F. (2016) Synthesis and Grafting of Carboxymethyl Cellulose from Environmental Pollutant Cellulosic Wastes of Textile Industry. Research Journal of Textile and Apparel, 20, 126-135. https://doi.org/10.1108/RJTA-08-2016-0018

[8] Jahan, I.A., Sultana, F., Islam, M.N., Hossain, M.A. and Abedin, J. (2007) Studies on 
Indigenous Cotton Linters for Preparation of Carboxymethyl Cellulose. Bangladesh Journal of Scientific and Industrial Research, 42, 29-36. https://doi.org/10.3329/bjsir.v42i1.352

[9] Pushpamalar, V., Langford, S.J., Ahmad, M. and Lim, Y.Y. (2006) Optimization of Reaction Conditions for Preparing Carboxymethyl Cellulose from Sago Waste. Carbohydrate Polymers, 64, 312-318. https://doi.org/10.1016/j.carbpol.2005.12.003

[10] Saputra, A.H., Qadhayna, L. and Pitaloka, A.B. (2014) Synthesis and Characterization of Carboxymethyl Cellulose (CMC) from Water Hyacinth Using EthanolIsobutyl Alcohol Mixture as the Solvents. International Journal of Chemical Engineering and Applications, 5, 36-40. https://doi.org/10.7763/IJCEA.2014.V5.347

[11] Sarkar, J. and Rasel, M.S. (2018) Sizing of Warp Yarn with a Different Concentration of Animal Fat and Acids and Determination of the Performance in Comparing with Conventional Sized Yarn. International Conference on Mechanical, Industrial and Energy Engineering, Khulna, Bangladesh, December 23-24.

[12] Yang, Y. and Reddy, N. (2013) Potential of Using Plant Proteins and Chicken Feathers for Cotton Warp Sizing. Cellulose, 20, 2163-2174. https://doi.org/10.1007/s10570-013-9956-9

[13] Lemeneh, D.Y. and Tesema, A.F. (2019) Valuation of Polyvinyl Alcohol and Maize Starch as Sizing Agent for Textile processing. International Journal of Modern Science and Technology, 4, 286-293.

[14] Baowei Q., Muxuan, L., Zhang, X., Chen, Y., Zhou, S., Liang, M. and Zou, H. (2021) Carboxymethyl Cellulose Sizing Repairs Carbon Fiber Surface Defects in Epoxy Composites. Materials Chemistry and Physics, 258, Article No. 123677. https://doi.org/10.1016/j.matchemphys.2020.123677

[15] Mohamed, Z.E.S., Amr, A., Knittel, D. and Schollmeyer, E. (2010) Synthesis and Application of New Sizing and Finishing Additives Based on Carboxymethyl Cellulose. Carbohydrate Polymers, 81, 769-774.

https://doi.org/10.1016/j.carbpol.2010.03.013 